\title{
HIF1a isoforms in benign and malignant prostate tissue and their correlation to neuroendocrine differentiation
}

\author{
Nastaran Monsef*1, Maria Soller2, loannis Panagopoulos² and Per Anders Abrahamsson ${ }^{3}$
}

\begin{abstract}
Background: Neuroendocrine (NE) differentiation in prostate cancer has been correlated with a poor prognosis and hormone refractory disease. In a previous report, we demonstrated the presence of immunoreactive cytoplasmic hypoxia inducible factor $1 \mathrm{a}(\mathrm{HIF} 1 \mathrm{a})$, in both benign and malignant NE prostate cells. HIF1a and HIF1 $\beta$ are two subunits of HIF1, a transcription factor important for angiogenesis. The aim of this study was to elucidate whether the cytoplasmic stabilization of HIF1a in androgen independent NE differentiated prostate cancer is due to the presence of certain HIF1a isoforms.

Methods: We studied the HIF1a isoforms present in 8 cases of benign prostate hyperplasia (BPH) and 43 cases of prostate cancer with and without NE differentiation using RT-PCR, sequencing analysis, immunohistochemistry and in situ hybridization.

Results: We identified multiple isoforms in both benign and malignant prostate tissues. One of these isoforms, HIF1a1.2, which was previously reported to be testis specific, was found in $86 \%$ of NE-differentiated prostate tumors, $92 \%$ of HIF1 a immunoreactive prostate tumors and $100 \%$ of cases of benign prostate hyperplasia.

Immunohistochemistry and in situ hybridization results showed that this isoform corresponds to the cytoplasmic HIF1a present in androgen-independent NE cells of benign and malignant prostate tissue and co-localizes with immunoreactive cytoplasmic HIF1ß.

Conclusion: Our results indicate that the cytoplasmic stabilization of HIF1a in NE-differentiated cells in benign and malignant prostate tissue is due to presence of an HIF1a isoform, HIF1a1.2. Co-localization of this isoform with HIF1 $\beta$ indicates that the HIF1a1.2 isoform might sequester HIF1 $\beta$ in the cytoplasm.
\end{abstract}

\section{Background}

Neuroendocrine (NE) cells in benign and malignant prostate tissue are characterized by expression of the NE marker chromogranin A and their specific morphology, including cytoplasmic extensions and dendritic processes. In addition, they lack androgen receptor and are therefore androgen-independent $[1,2]$. The majority of prostatic adenocarcinomas contain tumor cells with $\mathrm{NE}$ features which are present focally throughout the tumors. Several studies have shown that an increased number of NE cells in prostate cancer tissue and increased levels of circulating chromogranin A, an NE marker usually

\footnotetext{
*Correspondence: Nastaran.Monsef@gmail.com

${ }^{1}$ Department of Laboratory Medicine, Division of Pathology, Lund University Hospital, Sweden

Full list of author information is available at the end of the article
}

expressed in NE cells, are associated with a poor prognosis, tumor progression and androgen-independent disease $[1,2]$. It has been hypothesized that NE cells might affect the growth and proliferation of prostate tumors in an androgen receptor-independent way, probably through the secretion of NE peptides and autocrine/paracrine signaling pathways [1,3-6]. NE tumor cells in prostate cancer may also have a role in tumor angiogenesis. Increased expression of vascular endothelial growth factor (VEGF) in malignant NE cells and a higher density of microvessels around nests of such cells compared to areas of prostate cancer without these cells have been reported [7]. In a previous study, we demonstrated the presence of cytoplasmic hypoxia inducible factor $1 \alpha$ (HIF $1 \alpha)$ in a population of NE cells in benign and malignant prostate 
tissues [8]. HIFs are a family of transcription factors that are essential for angiogenesis and the adaptation of cells to hypoxia in both physiological and pathological processes $[9,10]$. The possible mechanisms behind HIF1 $\alpha$ stabilization and the function of cytoplasmic HIF $1 \alpha$ in NE cells of benign and malignant prostate tissues are not known. However, the complicated regulation of HIFs has been extensively studied in recent years. HIF1, which is composed of two subunits, HIF $1 \alpha$ and $\beta$, binds to the HRE of promoter regions and activates many genes involved in angiogenesis, glycolysis and anaerobic metabolism. In normoxia, the HIF1 $\alpha$ subunit is hydroxylated on specific proline residues (402 and 564) within the oxygen dependent domain (ODD) by specific oxygen-sensitive prolyl hydroxylases and, then ubiquitinated through the von Hippel-Lindau (VHL) dependent pathway and degraded instantly in the proteasome $[9,10]$. However, in hypoxic conditions, HIF1 $\alpha$ is stabilized by impaired function of these prolyl hydroxylases. After its interaction with a series of small proteins, such as P300 and CBP, the HIF $1 \alpha$ and $\beta$ complex translocates to the nucleus using its nuclear localizing signal (NLS) domains at C-and N-terminus and activates the cell's adaptive response to hypoxia $[9,10]$

There have been several previous reports on HIF1 $\alpha$ isoforms lacking several exons or displaying different exons than the wild type protein. Some of these isoforms encode cytoplasmic HIF1 $\alpha$ protein or proteins with altered transcriptional activity compared to the wild type protein. Regarding the N-terminal domain, two HIF1 $\alpha$ isoforms with different first exons have been identified: HIF $1 \alpha 1.2$, a protein with a different first and second exon which is 59 amino acids shorter than wild type HIF1 $\alpha$ and encodes a cytoplasmic protein specifically expressed in the human testis [11]; HIF $1 \alpha 1.3$, which is present in activated T-lymphocytes and encodes a functional protein with weaker transcriptional activity that the wild type protein [12]. At the C-terminal domain, isoforms lacking either exon 12 [13] or exons 11 and 12 [14] have been reported. Both isoforms have been shown to be stable cytoplasmic proteins and inhibit the function of fulllength HIF1 $\alpha$. Another shorter HIF $1 \alpha$ isoform lacking exon 14 has also been reported [15]. This isoform was shown to be 3 -fold less active than full-length HIF1 $\alpha$.

The aim of this study was to elucidate the mechanism behind the cytoplasmic stabilization of HIF1 $\alpha$ in NE cells of benign and malignant prostate tissues. We have investigated whether the cytoplasmic HIF $1 \alpha$ corresponds to any specific known isoform. Based on the sequences published by the National Center for Biotechnology Information (NCBI), we designed primers to amplify known HIF $1 \alpha$ isoforms and determined their presence in benign prostate hyperplasia and prostate cancer with and without NE differentiation.

\section{Methods}

\section{Study cases}

The present study included tissue obtained from 51 patients undergoing transurethral resection of the prostate (TURP): From 8 patients with obstructive voiding symptoms due to benign hyperplasia of the prostate $(\mathrm{BPH})$, and from 43 patients with prostate cancer. The majority of the patients in the latter group had previously received therapy and displayed hormone-refractory disease (Table 1). All tissue specimens were examined by a National Board certified pathologist (NM). This study was approved by the Ethics Committee of Lund University, and the Helsinki Declaration regarding the use of human tissue was followed.

\section{RNA preparation, RT-PCR and sequence analysis}

Total RNA was extracted from prostate tissue using TRIzol reagent (Invitrogen, Carlsbad, CA), and cDNA synthesis was conducted as described previously. To detect isoforms of HIF $1 \alpha$, PCR was performed with the primer sets shown in Table 2 . The $50-\mu$ l reaction volume contained $20 \mathrm{mM}$ Tris- $\mathrm{HCl}(\mathrm{pH} 8.4), 50 \mathrm{mM} \mathrm{KCl}, 1.5 \mathrm{mM}$

\section{Table 1: Characteristics of patients whose samples were} used in this study

Nr. of cases

\begin{tabular}{|c|c|}
\hline \multicolumn{2}{|l|}{ Age } \\
\hline$<65$ & 7 \\
\hline$\geq 65$ & 44 \\
\hline Benign prostate hyperplasia & 8 \\
\hline Adenocarcinoma & 43 \\
\hline \multicolumn{2}{|l|}{ Gleason Score } \\
\hline 5 & 1 \\
\hline 6 & 2 \\
\hline 7 & 11 \\
\hline 8 & 3 \\
\hline 9 & 13 \\
\hline 10 & 3 \\
\hline Non - determined & 10 \\
\hline \multicolumn{2}{|l|}{ Clinical stage } \\
\hline $\mathrm{T} 1$ & 3 \\
\hline $\mathrm{T} 2$ & 12 \\
\hline T3 & 19 \\
\hline T4 & 2 \\
\hline Non - determined & 7 \\
\hline $\begin{array}{l}\text { Hormone refractory } \\
\text { adenocarcinoma }\end{array}$ & 30 \\
\hline $\begin{array}{l}\text { Adenocarcinoma with non } \\
\text { determined hormonal state }\end{array}$ & 13 \\
\hline
\end{tabular}


Table 2: Primers used for amplification/sequencing and biotinylated oligonucleotide probes

\begin{tabular}{llll}
\hline & Forward primer 5'-3' & Reverse primer 5'-3' & $\begin{array}{l}\text { Size of amplified } \\
\text { fragment lengths (bp) }\end{array}$ \\
\hline HIF1a 1.1 & CACCTCTGGAC TTGCCTTCCTTC & CACCAGCATCCAG AAGTTTCCTCAC & 351 \\
aHIF1a 1.2 & ATGTGCAAGAC ACTGCATTCTTAG & CACCAGCATCCAG AAGTTCCTCAC & 220 \\
HIF1a 1.3 & TGGTGGTTACTC AGCACTTTTAGA & CACCAGCATCCAG AAGTTCCTCAC & - \\
HIF1a 10-13 & GGCAATGTCTCC ATTACCCACCG & CGCTTCTCTGAGC ATTCTGCAAG & 791 \\
HIF1a12 & GGTGGCATTACG AGTAGGTTCTTGT & AGGTCCCTATATC CCAATGGATGA & 180 \\
HIF1a 13-15 & ACTCAAAGTCGG ACAGCCTCACCA & ATCCATTGATTGC CCCAGCAGTC & 381 \\
Probe HIF1a 1.2 & Antisense, Biotin-GC AAGATATGTG CAAGACAC- & Sense, Biotin-GTGT CTTGCACAT ATCTTGC- & - \\
& Biotin & Biotin & \\
\hline
\end{tabular}

$\mathrm{MgCl}_{2}, 0.2 \mathrm{mM}$ of each dNTP, 1 unit Platinum Taq DNA polymerase (Invitrogen), $10 \mu \mathrm{M}$ of each of the forward and reverse primers and $1 \mu \mathrm{l}$ of cDNA. After an initial denaturation at $94^{\circ} \mathrm{C}$ for $5 \mathrm{~min}, 40$ cycles of $1 \mathrm{~min}$ at $94^{\circ} \mathrm{C}$, $1 \mathrm{~min}$ at $56^{\circ} \mathrm{C}$ and $1 \mathrm{~min}$ at $72^{\circ} \mathrm{C}$ were run using a Master cycler gradient (Eppendorf-Netheler. Hinz GmbH, Hamburg, Germany) termam cycler. The size of the amplified PCR product was determined on an agarose gel with $1 \mathrm{~kb}$ DNA ladder (cat. no. 15615-024, Invitrogen) and. For sequence analysis, the amplified fragments were purified using the Qiagen PCR purification kit (Qiagen), sequenced using the dideoxy procedure with an $\mathrm{ABI}$ Prism Big Dye terminator v1.1 cycle sequencing kit (PE Applied Biosystems) and the same primers as for PCR on an Applied Biosystems Model 3100-Avant Genetic Analyzer.

\section{In situ hybridization}

Biotinylated anti sense and sense olignucleotide probes were designed and purchased from Invitrogen (Table 2). Tissues were fixed in $4 \%$ formaldehyde, $4-\mu \mathrm{m}$-thick sections were cut and mounted on silanized slides (DAKO S3003), dewaxed with xylene for $10 \mathrm{~min}$ and rehydrated stepwise with $100 \%$ ethanol for $3 \mathrm{~min}$ and $70 \%$ ethanol for $3 \mathrm{~min}$. Endogenous peroxidase and biotin were blocked with peroxidase blocking solution (DAKO REAL, S2023) and biotin blocking system (DAKO, X0590) for $15 \mathrm{~min}$ each. The sections were then permeabilized with Proteinase K (DAKO S3020) and washed with Tris-buffered saline three times. Biotinylated probes designed for HIF1 $\alpha 1.2$ (Table 2, Invitrogen) were mixed in hybridization buffer (50\% formamide) at a concentration of $200 \mathrm{ng} /$ $\mathrm{ml}$. Probes were added to the sections, which were then covered with coverslips and heated at $92^{\circ} \mathrm{C}$ for $5 \mathrm{~min}$. Hybridization was carried out in a humid chamber at $37^{\circ} \mathrm{C}$ overnight. The sections were then washed in $2 \times$ SSC for $10 \mathrm{~min}$ followed by three washes in Tris-buffered saline. For detection of hybridization signals, the Gen Point Tyramid Signal Amplification System (Dako,
K0620) with chromogenic substrate (3.3'diaminobenzidine) was used according to the manufacturer's instructions.

\section{Immunohistochemistry}

Tissue samples were fixed in $4 \%$ buffered formalin and embedded in paraffin. One appropriate block from each specimen was selected and serial $4-\mu \mathrm{m}$-thick sections of tissue measuring at least $0,5 \times 0,5 \mathrm{~cm}$ was cut from the paraffin lock. The sections were used for immunohistochemical analysis and histological examination after hematoxylin and eosin staining. After deparaffinization and rehydration, the sections were heated in citrate buffer solution ( $\mathrm{pH} \mathrm{6)}$ for $14 \mathrm{~min}$ in a microwave oven for antigen retrieval. The characteristics and working concentrations of the antibodies used in this study are summarized in Table 3. Three primary HIF $1 \alpha$ antibodies with different epitopes were chosen; polyclonal antibody (AB1, Y-15, santa cruz) recognizing an epitope near the N-terminus of wild type HIF1 $\alpha$, monoclonal HIF1 $\alpha$ (Ab2, Novus Biological, NB 100-123), which recognizes an epitope in the middle of wild type HIF1 $\alpha$ (residues 432-528, corresponding to exon 10 and 11 of HIF1 $\alpha$ protein) and polyclonal HIF1 $\alpha$ (Ab3, Bethyl Laboratories), which recognizes a region between residues 775 and the $\mathrm{C}$-terminus (residue 826), corresponding to the exon 14 of HIF1 $\alpha$ protein. Chromogranin A was chosen as NE markers, and a polyclonal anti-chromogranin A antibody (DAKO, Denmark) was used. Immunohistochemical staining was carried out with LSAB+ System (HRP, K0670, DAKO, Denmark), according to the manufacturer's instructions. Sections were incubated with primary antibody at room temperature for $60 \mathrm{~min}$. Counterstaining was done with Mayer hematoxylin. Tumors with chromogranin A immunopositivity were considered NE-differentiated. The smallest chromogranin A immunopositive tumor area, detected in our study cases, contained 10 immunostained cells.

Double immunostaining was performed with combinations of primary antibodies for androgen receptor/chro- 
Table 3: Antibodies used for immunostaining

\begin{tabular}{|c|c|c|c|}
\hline Antibodies & Clone/Code & Dilution & Source \\
\hline HIF1a, Ab1 & $\begin{array}{l}\text { Goat } \\
\text { polyclonal } \\
\text { Y-15 }\end{array}$ & $1: 50$ & Santa Cruz \\
\hline HIF1a, Ab2 & $\begin{array}{l}\text { Mouse } \\
\text { monoclonal, } \\
\text { NB 100-123 }\end{array}$ & $1: 1000$ & Novus biological \\
\hline HIF1a, Ab3 & $\begin{array}{l}\text { Rabbit } \\
\text { polyclonal }\end{array}$ & $1: 500$ & Bethyl laboratories \\
\hline HIF1 $\beta$ & $\begin{array}{l}\text { Mouse } \\
\text { monoclonal, } \\
\text { ab465-100 }\end{array}$ & $1: 100$ & Abcam \\
\hline Androgen receptor, AR & $\begin{array}{l}\text { Mouse monoclonal } \\
\text { AR441 }\end{array}$ & $1: 1000$ & DAKO \\
\hline Chromogranin A & $\begin{array}{l}\text { Rabbit polyclonal } \\
\text { IHC00460 }\end{array}$ & $1: 1000$ & DAKO \\
\hline
\end{tabular}

mogranin A and HIF1 $\beta /$ HIF $1 \alpha A 3$. Double immunostaining kit (PicTure ${ }^{\mathrm{Tm}}$ Invitrogen, catalog nr. 87-9999) was used, according to the manufacturer's instructions. Goat anti mouse IgG HRP (horseradish peroxidase) conjugate used with DAB (3,3' Diaminobenzidine) produced a brown stain. Goat anti Rabbit IgG-AP polymer conjugate used with Fast red produced a red stain.

\section{Results}

\section{A broad range of HIF1a isoforms exists in benign and} malignant prostate tissues

HIF1 1.1 isoform was present in both benign and malignant prostate tissues (Table 4, Fig.1a). HIF1 1.2 was detected in 25 out of 43 cases of prostate cancer and in all cases of benign prostate hyperplasia (Table 4, Fig.1b). This isoform was expressed variably, although the signals from benign prostate tissues were very weak (Fig. 1b). We also found a correlation between this isoform and NE differentiation in prostate tumors. Eighty sex percent of prostate tumors with NE (compared to $28 \%$ of prostate tumors without NE) expressed this isoform (Table 4). Comparing the presence of this isoform with HIF1 $\alpha$ immunostaining showed that $92 \%$ of cases with this isoform also showed HIF1 $\alpha$ immunostaining (Table 4). Therefore, we suspect that the HIF $1 \alpha 1.2$ isoform represents the cytoplasmic HIF1 $\alpha$ in NE cells. The weak signals from benign prostate tissue can be explained by the fact that NE cells are rare in benign prostate tissue, making up only about $10 \%$ of the cells in the prostate gland. In addition, we used non-NE-differentiated LNCaP cells as a control, and these cells did not express this isoform, further indicating that it represents cytoplasmic HIF1 $\alpha$ (Fig. $1 \mathrm{~g}$, lane 2).

HIF1 $\alpha 1.3$ was not detected in any of our study cases (Table 4, Fig.1c). Since inflammation was rare in our specimen, this further verifies a report showing the presence of this isoform of HIF $1 \alpha$ in activated lymphocytes. However, we lacked positive control for HIF1 $\alpha 1.3$.

To investigate various isoforms with alternative splicing of exons 11 to 13, we used forward primers located in the middle of exon 10 and reverse primers located in the middle of exon 13. We noted one strong band of $220 \mathrm{bp}$ and a weaker band of 340 bp (Fig. 1d). Sequence analysis of the shorter band showed only part of exons 10 and 13, indicating the presence of an HIF1 $\alpha$ isoform without exons 11 and 12. Sequence analysis of the weaker band of $340 \mathrm{bp}$ was not possible, but the size of the band corresponds to an isoform lacking exon12. These two isoforms were found in both benign and malignant cases. In one case of benign prostate hyperplasia and three cases of malignant prostate tissue, we also detected a band at 720 bp, which might correspond to HIF1 $\alpha$ containing exons 11 and 12. As a control, we analyzed LNCaP cells, which showed a strong band of 720bp (Fig. 1g, lane 5). Sequence analysis verified that the band corresponds to exons 10 , 11 and 12 as well as a part of exon 13.

To further investigate the presence of exon 12 in benign and malignant prostate tissues, we designed primers located in the beginning and end of exon 12 (Table 2). We identified exon 12 in all study cases (Fig. 1e). We conclude that the first experiment using primers located in exons 10 and 13 was not optimal to detect the longer HIF $1 \alpha$ isoform containing exon 12 . We also conclude that in most cases of benign prostate hyperplasia and prostate cancers, the $H I F 1 \alpha$ isoform containing exon 12 is expressed at very low levels since $\mathrm{LNCaP}$ cells had high signals with the same primers (Fig. 1g, lane 5).

$H I F 1 \alpha$ variants with and without exon 14 (HIF $1 \alpha 14+$ and 14-) were detected in all cases of benign prostate hyperplasia and prostate cancer. With primers located in 

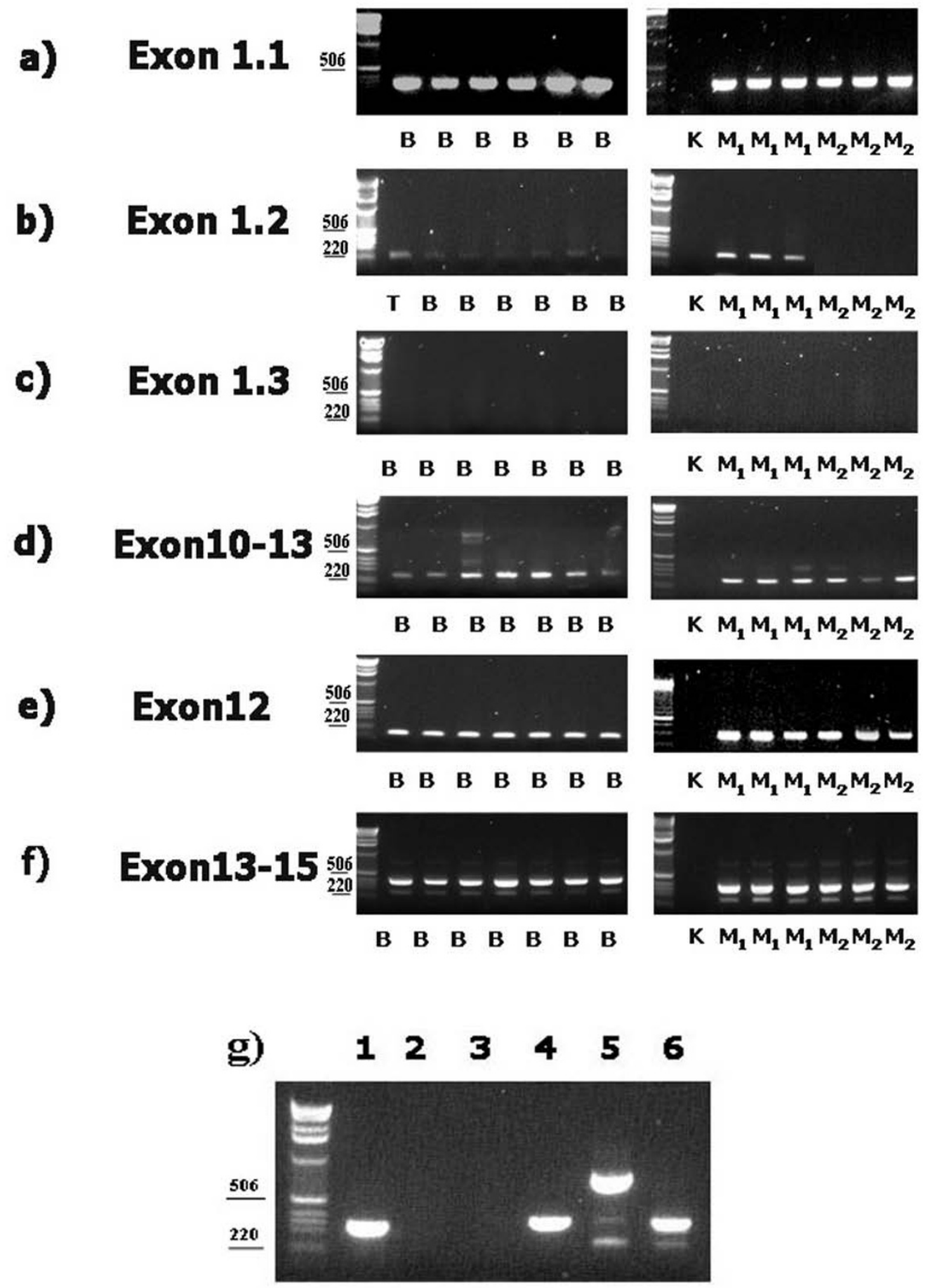

Figure 1 RT-PCR analysis of HIF1 a mRNA isoforms in benign prostate hyperplasia (B, Fig. 1a-f), NE differentiated prostate cancer (M1, Fig.1 a-f)) and non NE differentiated prostate cancer (M2, Fig. 1a-f)). K (Fig. 1a-f) and T (Fig. 1b) correspond to control and testis tissue, respectively. HIFla isoforms in LNCaP cells (Fig. 1g), Lane 1 represents HIF1 1 1.1, lane 2 represents HIF1a1.2, and lane 3 represents HIF1a1.3. Lane 4: bands detected with primers sets located in exons 10 and 13, lane 5 includes bands from primers located in exon 12 and lane 6 corresponds to bands detected with primers located in exons 13 and 15 
Table 4: The frequency of HIF1a isoforms in benign prostate hyperplasia and prostate cancer with and without NE.

\begin{tabular}{|c|c|c|c|c|c|c|c|c|c|}
\hline Table 4 & Total nr. & HIF1a 1.1 & HIF1a 1.2 & HIF1a 1.3 & HIF1a 12+ & HIF1a 12- & HIF1a 11-\&12- & HIF1a 14+ & HIF1a 14- \\
\hline Benign & 8 & $8(100 \%)$ & $8(100 \%)$ & 0 & $8(100 \%)$ & $8(100 \%)$ & $8(100 \%)$ & $8(100 \%)$ & $8(100 \%)$ \\
\hline Adenocarcinoma & 43 & $43(100 \%)$ & $25(58 \%)$ & 0 & $43(100 \%)$ & $43(100 \%)$ & $43(100 \%)$ & $43(100 \%)$ & $43(100 \%)$ \\
\hline Adenocarcinoma immunopositive for HIF1a & 26 & $26(100 \%)$ & $24(92 \%)$ & 0 & $26(100 \%)$ & $26(100 \%)$ & $26(100 \%)$ & $26(100 \%)$ & $26(100 \%)$ \\
\hline Adenocarcinoma immunonegative for HIF1a & 17 & $17(100 \%)$ & $1(6 \%)$ & 0 & $17(100 \%)$ & $17(100 \%)$ & $17(100 \%)$ & $17(100 \%)$ & $17(100 \%)$ \\
\hline Adenocarcinoma with NE & 22 & $22(100 \%)$ & $19(86 \%)$ & 0 & $22(100 \%)$ & $22(100 \%)$ & $22(100 \%)$ & $22(100 \%)$ & $22(100 \%)$ \\
\hline Adenocarcinoma Without NE & 21 & $21(100 \%)$ & $6(28 \%)$ & 0 & $21(100 \%)$ & $21(100 \%)$ & $21(100 \%)$ & $21(100 \%)$ & $21(100 \%)$ \\
\hline LNCaP & & + & - & - & + & + & + & + & + \\
\hline
\end{tabular}

The LNCaP cells were used as a control 
exons 13 and 15, we detected two bands corresponding to these two isoforms (Fig. 1f).

LNCaP cells were used as control for analysis of $H I F 1 \alpha 1.1, H I F 1 \alpha 12+/-$, and HIF $1 \alpha 14+/-. H I F 1 \alpha 1.2$ and 1.3 were not detected in these cells (Fig. 1g, lanes 1,2,3 and 6).

\section{Cytoplasmic HIF1a in NE cells from prostate tumors has an different $\mathrm{N}$-terminus than the wild type protein}

To differentiate the isoforms of HIF1 $\alpha$, we used three different antibodies that recognize the $\mathrm{N}$-terminus of wild type protein (Y-10 Santa Cruz, Ab1, corresponding to exons 1-2, Figs.2a and 2c), the middle section of wild type protein (NB 100-123, Ab2, corresponding to exons 10-11, Figs. 2a,b,d) and the C-terminus (Bethyl Laboratories Ab3, corresponding to exon 14, Figs. Fig. 2a,b,e). Immunostaining was performed on serial sections of benign prostate hyperplasia and HIF1 $\alpha$ prostate cancer tissues. The antibody recognizing the $\mathrm{N}$-terminus of wild type

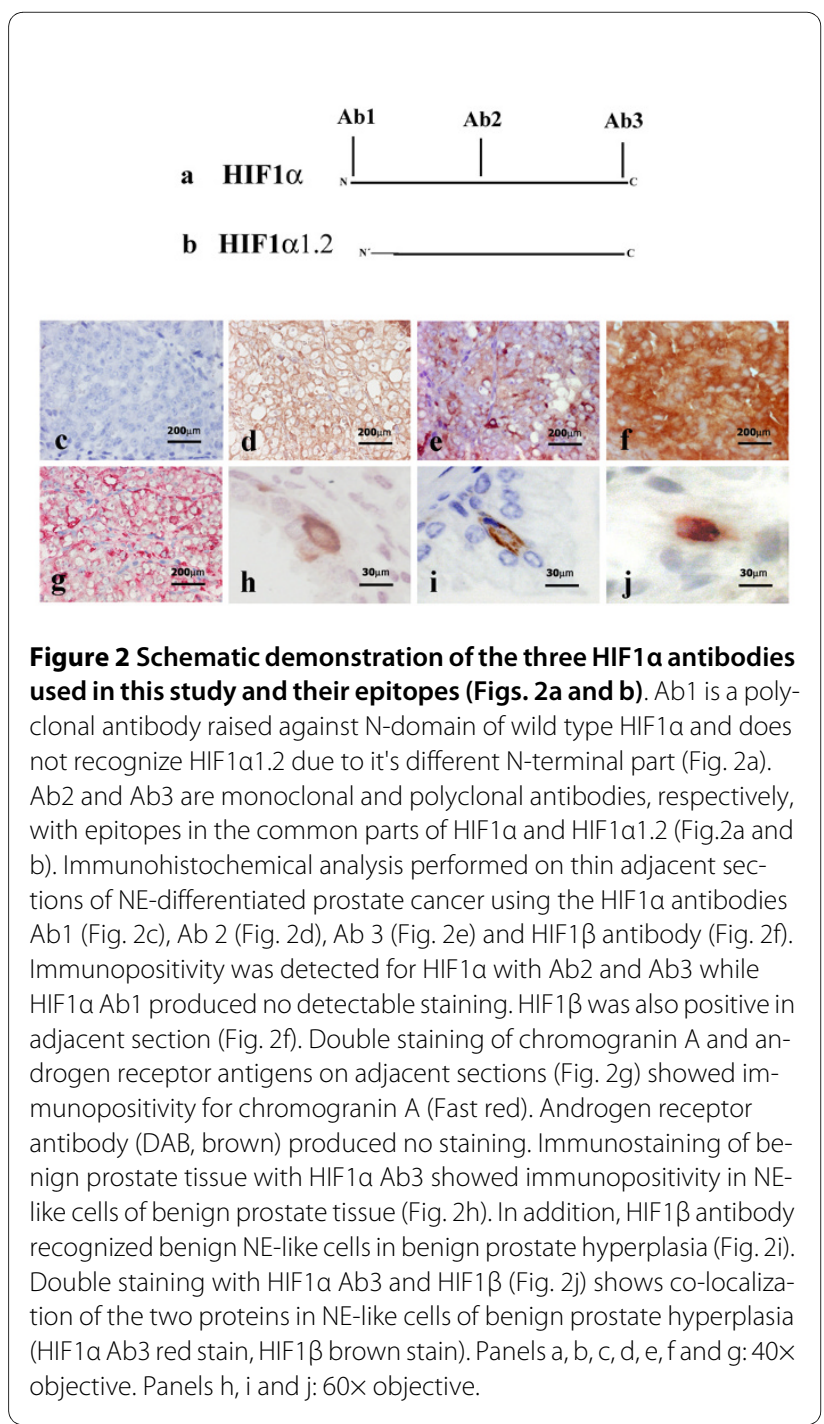

HIF $1 \alpha$ failed to detect cytoplasmic HIF $1 \alpha$ in malignant cells of prostate tissue (Fig.2c), whereas positive immunostaining was seen with the other two antibodies (Figs. $2 \mathrm{~d}$ and $2 \mathrm{e})$. The same results were shown with benign prostate tissue (Not shown). These results indicate that the cytoplasmic HIF1 $\alpha$ detected in the NE cells of benign and malignant cells contains an $\mathrm{N}$-terminal portion different from the wild type protein.

\section{Co-localization of HIF $1 \alpha$ and HIF $1 \beta$ in androgen receptor-} negative benign and malignant NE-like cells of the prostate Immunostaining for HIF1 $\beta$ showed cytoplasmic staining in NE-like cells of benign prostate tissue (Fig. 2i). In order to investigate whether the immunoreactive HIF1 $\beta$ colocalizes with HIF1 $\alpha$ in benign prostate tissue, we selected two cases of benign prostate hyperplasia for double immunostaining. We observed co-localization of cytoplasmic HIF1 $\alpha$ with cytoplasmic HIF1 $\beta$ in all NE cells of the benign prostate tissue (53 cells counted) (Fig. $2 j$ ). We also investigated the localization of HIF $1 \alpha$ and HIF $1 \beta$ using immunostaining of serial sections of two cases with NE and non-NE prostate tumors. HIF $1 \beta$ was seen in approximately $80 \%-100 \%$ of HIF $1 \alpha$-positive NEdifferentiated tumor cells (Figs. 2e and 2f). In addition, double staining in malignant HIF $1 \alpha$-immunopositive cells showed that these cells were immunonegative for androgen receptor (Fig. $2 \mathrm{~g}$ ). In non-NE prostate tumors we found no detectable cytoplasmic HIF1 $\beta$ immunostaining. Only weak nuclear HIF1 $\beta$ staining was observed in these tumors (data not shown).

\section{In situ hybridization shows the presence of HIF1.2a in NE- differentiated benign and malignant prostate cells} In situ hybridization was performed on serially cut paraffin sections from two cases of benign and four cases of malignant prostate cancer. Two cases of adenocarcinomas were previously shown to contain cells with cytoplasmic HIF1 $\alpha$ and NE marker, chromogranin. The other two cases were negative for cytoplasmic HIF $1 \alpha$ and NE marker. In adjacent sections, the majority of HIF $1 \alpha$ positive cells in both benign and malignant cells (93\% versus $89 \%)$ also displayed increased HIF $1 \alpha 1.2$ specific mRNA levels (Figs. 3a,c, g, i, j). Fifty cells were counted in the benign cases, and 300 cells were counted in the malignant tissue. The HIF1 $\alpha$-negative cells had low or no detectable mRNA levels of HIF1 $\alpha$ (Figs. 3e and 3f). These findings suggest that HIF1 $\alpha 1.2$ corresponds to the isoform encoding cytoplasmic HIF $1 \alpha$ in both benign and malignant prostate tissues.

\section{Discussion}

HIF1 $\alpha$, a major transcription factor essential in tumorigenesis, has been shown to be over-expressed in many types of tumors, including prostate cancer [16-18]. Neo- 


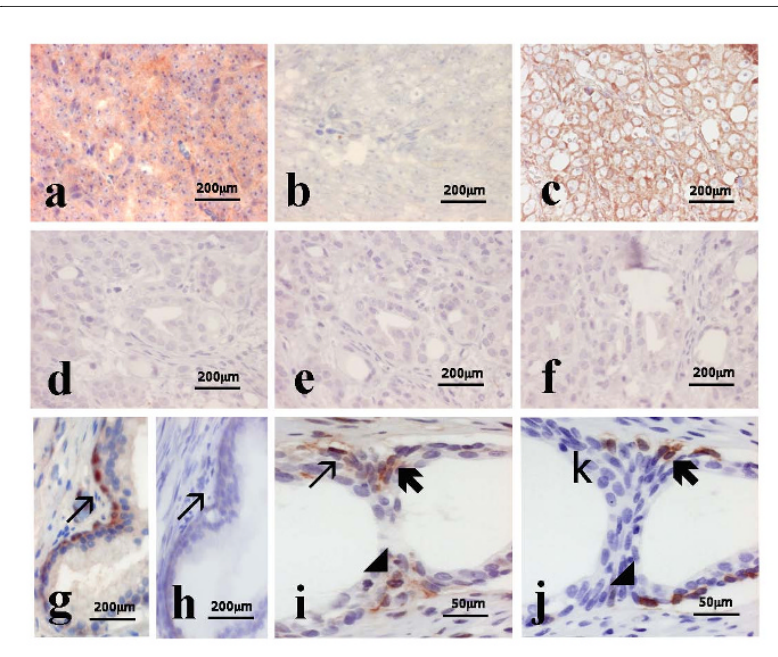

Figure 3 Results of in situ hybridization and immunohistochemistry on thin adjacent section to detect expression of HIF-1a1.2 mRNA and HIF1a protein in malignant and benign prostate tissue. In situ hybridization (antisense probe, Fig. 3a) and immunostaining with HIF1a Ab2 (Fig. 3c) on thin adjacent sections of NEdifferentiated prostate adenocarcinoma showed co-localization of HIF1a1.2 transcript and HIF-1 a protein. Incubation with sense probe did not generate any detectable hybridization signals (Fig. 3b). Both /n situ hybridization (Fig. 3d antisense) and $\mathrm{HIF-1a} \mathrm{Ab2} \mathrm{immunostaining}$ (Fig. 3f) were negative in non-NE-differentiated prostate adenocarcinoma. In situ hybridization with sense probe performed on non-NE-differentiated prostate cancer (Fig. 3e) was negative. In situ hybridizering on benign prostate tissue showed HIF1a 1.2 transcript in NE-like cells of benign prostate tissue (Fig. $3 \mathrm{~g}, \mathrm{\kappa}$ ). The sense probe on thin adjacent section generated no signals (Fig. 3h, $\mathrm{\kappa}$ ). Furthermore, co-localization of HIF1a 1.2 transcript (Fig. 3i,K, $\psi, \Sigma$ ) and HIF1 a protein, detected with HIF1aAb3 (Fig. $3 j, \kappa, \psi, \Sigma$ ) was also shown in NE-like cells of benign prostate tissue. Panels a, b, c, d, e, f, g, h, i, j: 40× objective.

angiogenesis occurs in an uncoordinated fashion in malignant tumors, leading to hypoxia, inactivation of prolyl hydroxylases and inhibition of HIF1 $\alpha$ degradation, which, in turn, activates HIF1 $\alpha$ [19]. HIF1 $\alpha$ protein has also been shown to be stabilized under normoxic conditions by growth factor stimulation or due to mutations in the VHL protein [20]. The accumulation of HIF1 $\alpha$ protein has been reported to be an early event in prostate cancer and high-grade prostatic intraepithelial neoplasia (HGPIN) [21,22]. The accumulation of wild type HIF1 $\alpha$ should lead to its nuclear transport, unless regulatory parts are defective or missing. One possible explanation for the cytoplasmic stabilization of the protein is the presence of certain HIF1 $\alpha$ isoforms. Indeed, in this study, we have shown that a broad range of HIF $1 \alpha$ isoforms are present in both benign prostate hyperplasia and prostate tumors. We have shown by PCR, immunohistochemistry and in situ hybridization that the previously reported testis-specific isoform, HIF1 1.2 corresponds to cytoplasmic HIF $1 \alpha$ in NE-differentiated benign and malignant prostate cells. HIF1 $\alpha 1.2$, which lacks one of the NLS domains responsible for nuclear transport, was shown to accumulate in the cytoplasm and has also been shown in a previous study to have inhibitory effects on full-length HIF in human sperms [11]. The authors of that study speculated that inhibition of full-length HIF1 $\alpha$ might be essential for the function of hypoxic sperm. A similar function for cytoplasmic HIF1 $\alpha$ in benign and malignant prostate cells might be considered. In addition, co-localization of cytoplasmic HIF $1 \alpha$ and HIF $1 \beta$ in this study indicates that this isoform might sequester HIF1 $\beta$ in the cytoplasm. Other reports confirm a similar function for cytoplasmic HIF1 $\alpha$. Stimulation of HEK293 cells with zinc induces a cytoplasmic spliced variant of HIF1 $\alpha$ without exon 12 [23]. This 557-amino-acid isoform was shown to sequester HIF1 $\beta$ in the cytoplasm and therefore to inhibit wild type HIF1 $\alpha$. Due to a frame shift mutation, the isoform is shortened and lacks both trans activating domains and the $\mathrm{C}$-terminal nuclear localizing signal domain. Another cytoplasmic spliced variant of human HIF1 $\alpha$ (516 amino acids in length) represents a stable, short isoform without exons 11 and 12 [14]. Similarly to the variant lacking only exon 12 , this isoform was identified as a dominant negative due to its association with HIF1 $\beta$ in the cytoplasm.

Recent studies have shown an association between hypoxia inducible factor and androgen receptor. The androgen receptor activates HIF1 $\alpha$, leading to upregulation of hypoxia inducible factor gene products $[24,25]$. In addition, hypoxia has been shown to increase androgen receptor sensitivity [26] and androgen receptor induced expression of the human PSA gene in a prostate cancer cell line [27]. Malignant NE cells which have been shown to increase in number after hormonal treatment, are usually androgen independent and only occasionally express androgen receptor and PSA [1]. As, we have shown here, the NE differentiated tumor cells display an isoform with a possible inhibitory effect on the wild type HIF $1 \alpha$ protein, indicating that the androgen independent malignant NE cells might also be independent of HIF1 $\alpha$ for their survival and tumorogenesis.

Malignant NE cells have been correlated with increased microvessel density in prostate tumors and display increased expression of VEGF, an important angiogenic regulatory factor. The functional implication of cytoplasmic HIF $1 \alpha$ and its relationship to VEGF remain to be elucidated. HIF1 $\alpha$ is a key regulatory transcription factor of VEGF, but VEGF has also been shown to be regulated by other transcriptions factors. For example, RaIA uppregulates VEGF-C in prostate cancer cells during androgen ablation [28] and STAT3 binds to the VEGF promoter and directly regulates VEGF [29]. If cytoplasmic HIF1 $\alpha$ in NE cells exerts an inhibitory effect on full-length HIF1 $\alpha$, this might indicate that VEGF is up-regulated in NE cells by other transcription factors. 


\section{Conclusion}

In summary, our results suggest that cytoplasmic HIF1 $\alpha$ in androgen independent NE cells of benign prostate tissue and non NE differentiated prostate tumors, corresponds to HIF1 $\alpha 1.2$ isoform. Co-localization of this isoform with immunoreactive cytoplasmic HIF1 $\beta$ indicates that the HIF1 $\alpha 1.2$ isoform, which lacks one of the protein's nuclear translocation signals, may sequester HIF1 $\beta$ in the cytoplasm.

\section{Completing interests}

The authors declare that they have no competing interests.

\section{Authors' contributions}

NM and IP conceived of the study, NM carried out the design and the experiments. NM, IP, MS, PAA participated in the analysis of results. NM wrote the manuscript. IP, MS and PAA reviewed the manuscript. All authors have read and approved the final manuscript.

\section{Acknowledgements}

Financial support: This study was supported by the Gunnar Nilsson Cancer Foundation, grant no. P95/07, The Swedish Research Council, grant no. k2007G7X-20443-01-3 and the Swedish Childhood Cancer Foundation grant no. PROJ07/013.

\section{Author Details}

'Department of Laboratory Medicine, Division of Pathology, Lund University Hospital, Sweden, 2Department of Clinical Genetics, Lund University Hospital, Sweden and ${ }^{3}$ Department of Clinical Sciences, Division of Urological Cancer, Malmö University Hospital, Lund University, Sweden

Received: 18 January 2010 Accepted: 21 July 2010

Published: 21 July 2010

\section{References}

1. Vashchenko N, Abrahamsson PA: Neuroendocrine differentiation in prostate cancer: implications for new treatment modalities. Eur Urol 2005, 47(2):147-155

2. Bonkhoff $\mathrm{H}$, Fixemer T: Neuroendocrine differentiation in prostate cancer: an unrecognized and therapy resistant phenotype. Pathologe 2005, 26(6):453-460

3. Dizeyi N, Bjartell A, Nilsson E, Hansson J, Gadaleanu V, Cross N, Abrahamsson PA: Expression of serotonin receptors and role of serotonin in human prostate cancer tissue and cell lines. Prostate 2004, 59(3):328-336.

4. Moody TW, Chan D, Fahrenkrug J, Jensen RT: Neuropeptides as autocrine growth factors in cancer cells. Curr Pharm Des 2003, 9(6):495-509.

5. Carraway RE, Hassan S: Neurotensin receptor binding and neurotensininduced growth signaling in prostate cancer PC3 cells are sensitive to metabolic stress. Regul Pept 2007, 141(1-3):140-153.

6. Siddiqui EJ, Shabbir M, Mikhailidis DP, Thompson CS, Mumtaz FH: The role of serotonin (5-hydroxytryptamine1 $\mathrm{A}$ and $1 \mathrm{~B}$ ) receptors in prostate cancer cell proliferation. J Urol 2006, 176(4 Pt 1):1648-1653.

7. Partanen TA, Arola J, Saaristo A, Jussila L, Ora A, Miettinen M, Stacker SA, Achen MG, Alitalo K: VEGF-C and VEGF-D expression in neuroendocrine cells and their receptor, VEGFR-3, in fenestrated blood vessels in human tissues. Faseb J 2000, 14(13):2087-2096.

8. Monsef N, Helczynski L, Lundwall A, Pahlman S: Localization of immunoreactive HIF-1 alpha and HIF-2alpha in neuroendocrine cells of both benign and malignant prostate glands. Prostate 2007, 67(11):1219-1229.

9. Semenza GL: Hypoxia-inducible factor 1 and cancer pathogenesis. IUBMB Life 2008, 60(9):591-597.

10. Zhou J, Schmid T, Schnitzer S, Brune B: Tumor hypoxia and cancer progression. Cancer Lett 2006, 237(1):10-21.

11. Depping R, Hagele S, Wagner KF, Wiesner RJ, Camenisch G, Wenger RH, Katschinski DM: A dominant-negative isoform of hypoxia-inducible factor-1 alpha specifically expressed in human testis. Biol Reprod 2004, 71(1):331-339.

12. Lukashev D, Sitkovsky M: Preferential expression of the novel alternative isoform 1.3 of hypoxia-inducible factor 1alpha in activated human $T$ lymphocytes. Hum Immunol 2008, 69(7):421-425.

13. Chun YS, Choi E, Yeo EJ, Lee JH, Kim MS, Park JW: A new HIF-1 alpha variant induced by zinc ion suppresses HIF-1-mediated hypoxic responses. J Cell Sci 2001, 114(Pt 22):4051-4061.

14. Chun YS, Choi E, Kim TY, Kim MS, Park JW: A dominant-negative isoform lacking exons 11 and 12 of the human hypoxia-inducible factor-1alpha gene. Biochem J 2002, 362(Pt 1):71-79.

15. Gothie E, Richard DE, Berra E, Pages G, Pouyssegur J: Identification of alternative spliced variants of human hypoxia-inducible factor-1alpha. J Biol Chem 2000, 275(10):6922-6927.

16. Kimbro KS, Simons JW: Hypoxia-inducible factor- 1 in human breast and prostate cancer. Endocr Relat Cancer 2006, 13(3):739-749.

17. Korkolopoulou P, Patsouris E, Konstantinidou AE, Pavlopoulos PM, Kavantzas N, Boviatsis E, Thymara I, Perdiki M, Thomas-Tsagli E, Angelidakis $D$, et al: Hypoxia-inducible factor 1alpha/vascular endothelial growth factor axis in astrocytomas. Associations with microvessel morphometry, proliferation and prognosis. Neuropathol App/ Neurobiol 2004, 30(3):267-278

18. Luo Y, He DL, Ning L, Shen SL, Li L, Li X: Hypoxia-inducible factor-1alpha induces the epithelial-mesenchymal transition of human prostatecancer cells. Chin Med J (Engl) 2006, 119(9):713-718.

19. Semenza GL, Shimoda LA, Prabhakar NR: Regulation of gene expression by HIF-1. Novartis Found Symp 2006, 272:2-8. discussion 8-14, 33-16

20. Page EL, Chan DA, Giaccia AJ, Levine M, Richard DE: Hypoxia-inducible factor-1alpha stabilization in nonhypoxic conditions: role of oxidation and intracellular ascorbate depletion. Mol Bio/ Cell 2008, 19(1):86-94.

21. Zhong H, Semenza GL, Simons JW, De Marzo AM: Up-regulation of hypoxia-inducible factor 1alpha is an early event in prostate carcinogenesis. Cancer Detect Prev 2004, 28(2):88-93.

22. Hao P, Chen X, Geng H, Gu L, Chen J, Lu G: Expression and implication of hypoxia inducible factor-1alpha in prostate neoplasm. J Huazhong Univ Sci Technolog Med Sci 2004, 24(6):593-595.

23. Chun YS, Lee KH, Choi E, Bae SY, Yeo EJ, Huang LE, Kim MS, Park JW: Phorbol ester stimulates the nonhypoxic induction of a novel hypoxiainducible factor 1alpha isoform: implications for tumor promotion. Cancer Res 2003, 63(24):8700-8707.

24. Boddy JL, Fox SB, Han C, Campo L, Turley H, Kanga S, Malone PR, Harris AL: The androgen receptor is significantly associated with vascular endothelial growth factor and hypoxia sensing via hypoxia-inducible factors HIF-1a, HIF-2a, and the prolyl hydroxylases in human prostate cancer. Clin Cancer Res 2005, 11(21):7658-7663.

25. Rudolfsson SH, Bergh A: Testosterone-stimulated growth of the rat prostate may be driven by tissue hypoxia and hypoxia-inducible factor-1alpha. J Endocrinol 2008, 196(1):11-19.

26. Park SY, Kim YJ, Gao AC, Mohler JL, Onate SA, Hidalgo AA, Ip C, Park EM, Yoon SY, Park YM: Hypoxia increases androgen receptor activity in prostate cancer cells. Cancer Res 2006, 66(10):5121-5129.

27. Horii K, Suzuki Y, Kondo Y, Akimoto M, Nishimura T, Yamabe Y, Sakaue M, Sano T, Kitagawa T, Himeno S, et al:: Androgen-dependent gene expression of prostate-specific antigen is enhanced synergistically by hypoxia in human prostate cancer cells. Mol Cancer Res 2007, 5(4):383-391.

28. Rinaldo F, Li J, Wang E, Muders M, Datta K: RalA regulates vascular endothelial growth factor-C (VEGF-C) synthesis in prostate cancer cells during androgen ablation. Oncogene 2007, 26(12):1731-1738.

29. Niu G, Wright KL, Huang M, Song L, Haura E, Turkson J, Zhang S, Wang T, Sinibaldi D, Coppola D, et al.: Constitutive Stat3 activity up-regulates VEGF expression and tumor angiogenesis. Oncogene 2002, 21(13):2000-2008.

Pre-publication history

The pre-publication history for this paper can be accessed here: http://www.biomedcentral.com/1471-2407/10/385/prepub

doi: 10.1186/1471-2407-10-385

Cite this article as: Monsef et al., HIF1? isoforms in benign and malignant prostate tissue and their correlation to neuroendocrine differentiation BMC Cancer 2010, 10:385 